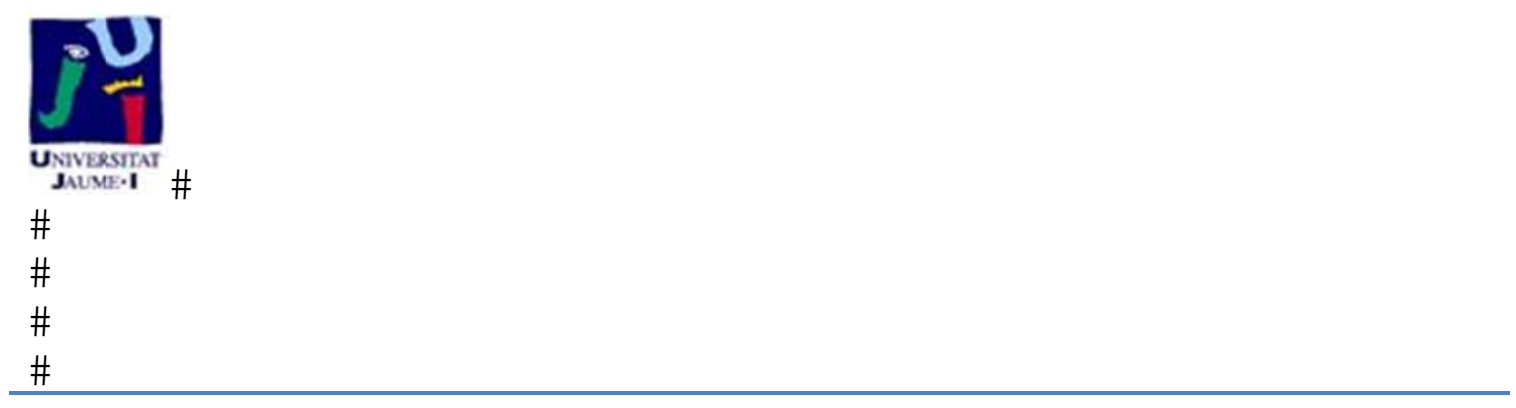

Título artículo / Títol article: Effectiveness of cognitive behavioral therapy supported by virtual reality in the treatment of body image in eating disorders: one year follow-up

Autores / Autors

Botella Arbona, Cristina ; Perpiñá Tordera, Concha ; Marco Salvador, José Heliodoro

Revista:

Psychiatry research

Versión / Versió:

Postprint de l'autor

Cita bibliográfica / Cita

MARCO, José H.; PERPIÑÁ, Conxa; BOTELLA, bibliogràfica (ISO 690):

Cristina. Effectiveness of cognitive behavioral therapy supported by virtual reality in the treatment of body image in eating disorders: One year followup. Psychiatry research, 2013, vol. 209, no 3, p. 619625

url Repositori UJI:

http://repositori.uji.es/xmlui/handle/10234/93401

\# 


\title{
Effectiveness of cognitive behavioral therapy supported by virtual reality in the treatment of body image in eating disorders: One year follow-up
}

\author{
José H. Marco ${ }^{\mathrm{a}, *}$, Conxa Perpiñá ${ }^{\mathrm{b}, \mathrm{d}}$, Cristina Botella ${ }^{\mathrm{c}, \mathrm{d}}$ \\ ${ }^{a}$ Department of Personality, Assessment and Treatment in Health Science, Catholic University of Valencia, Valencia, Spain \\ ${ }^{\mathrm{b}}$ Department of Personality, Assessment and Psychological Treatment, University of Valencia, Valencia, Spain \\ ${ }^{\mathrm{c}}$ Department of Basic Psychology, Clinic and Psychobiology, Universitat Jaume I, Castellón, Spain \\ ${ }^{\mathrm{d}}$ CIBER Fisiopatologia Obesidad y Nutrición (CB06/03), Instituto Salud Carlos III, Spain
}

\section{A R T I C L E I N F O}

\section{Article history:}

Received 1 February 2012

Received in revised form

23 July 2012

Accepted 14 February 2013

\section{Keywords:}

Cognitive-behavioral-treatment

Anorexia

Bulimia nervosa

Virtual systems

Outpatient

Personality disorders

Randomized controlled trial

\begin{abstract}
A B S T R A C T
Body image disturbance is a significant maintenance and prognosis factor in eating disorders. Hence, existing eating disorder treatments can benefit from direct intervention in patients' body image. No controlled studies have yet compared eating disorder treatments with and without a treatment component centered on body image. This paper includes a controlled study comparing Cognitive Behavioral Treatment (CBT) for eating disorders with and without a component for body image treatment using Virtual Reality techniques. Thirty-four participants diagnosed with eating disorders were evaluated and treated. The clinical improvement was analyzed from statistical and clinical points of view. Results showed that the patients who received the component for body image treatment improved more than the group without this component. Furthermore, improvement was maintained in post-treatment and at one year follow-up. The results reveal the advantage of including a treatment component addressing body image disturbances in the protocol for general treatment of eating disorders. The implications and limitations of these results are discussed below.
\end{abstract}

(c) 2013 Elsevier Ireland Ltd. All rights reserved.

\section{Introduction}

Body image disturbance is one of the most prominent clinical characteristics of eating disorders (Garner, 2002; Stice, 2002; Schwartz and Brownell, 2004; Nye and Cash, 2006). Body image is also one of the most relevant prognostic factors in the treatment of bulimia nervosa (BN) (Fairburn et al., 1993; Stice and Shaw, 2002) and anorexia nervosa (AN) (Thompson, 1992; Gleaves et al., 1993). Dissatisfaction with one's body as well as body image disturbance is associated with problematic behaviors and attitudes toward food, such as lack of control over eating, adopting restrictive diets, and demonstrating bulimic symptomatology. Therefore, the persistence of body dissatisfaction after treatment of eating disorders is a reliable predictor of relapse in AN and BN patients (Shisslak and Crago, 2001; Stice, 2002; Cash and Hrabosky, 2004). Despite the relevance of body image in eating disorder treatment, most studies fail to evaluate or treat body image (Rosen, 1996). In cases where body image is a treatment target, the effect of the treatment on patients' body image is not analyzed (Farrell et al., 2006). Psychoeducational treatment for BN, pure behavioral

\footnotetext{
* Correspondence to: Department of Personality, Assessment and Treatment in Health Science, Catholic University of Valencia, C/Guillem de Castro, 175, Valencia 46008, Spain. Tel.: + 34963637412 ; fax: + 34963919827.

E-mail addresses: joseheliodoro.marco@ucv.es, jh.marco@hotmail.com (J.H. Marco).
}

treatments, pharmacological treatments, interpersonal therapy, and psychodynamic therapy are ineffective in terms of global body image improvement (Cash and Grant, 1996). Some treatments for eating disorders (Thompson et al., 1996) include educational components addressing body image in BN (Fairburn, 2002) and AN (Vitousek, 2002); however the effect of these interventions on body image is unknown (Nye and Cash, 2006).

From a transdiagnostic perspective (Fairburn et al., 2003), body image intervention must prevent the maintenance of eating disorder psychopathology. Fairburn et al. (2009) enhanced Cognitive Behavioral Treatment (CBT) for eating disorders with other components addressing important aspects of these disorders including perfectionism, interpersonal problems, and self-esteem. Several studies (Rosen 1996; Farrell et al., 2006; Nye and Cash, 2006) suggest that interventions based on body image distortion could improve evidence-based treatments for eating disorders (NICE, 2004) However, there has been no controlled study proving the effectiveness of body image treatment in eating disorders (Nye and Cash, 2006). Hence, it would be illuminating to compare the statistical and clinical effectiveness of treatments with or without a component focused on body image (Cash and Hrabosky, 2004; Farrell et al., 2006).

A previous study conducted by our group with participants diagnosed with eating disorders showed that treatment for body image disturbances is more effective using CBT based on VR techniques than using traditional CBT treatment alone (Perpiñá 
et al., 1999). Two treatment conditions were established in that study. In one condition, CBT for body image was applied in eight group sessions as well as six individual sessions with VR (Perpiñá et al., 2000), a total of 14 sessions. In the other condition, we applied CBT for body image in eight group sessions without VR as well as six relaxation sessions (which were included so that both groups had the same number of sessions) (Perpiñá et al., 1999). We found that in participants with serious eating disorders, the number of sessions was not as important as their content. Furthermore, treatment centered on body image reduced both the eating disorder psychopathology and the secondary psychopathology (depression, anxiety, negative emotions); these results persisted at the one year followup (Perpiñá et al., 1999). One of the limitations of that study was that the participants had undergone various eating disorder treatments prior to our intervention.

Information and Communication Technologies (ICT) are widely used as therapeutic tools in the field of neuropsychology (Rizzo et al., 1998) and also in the treatment of anxiety disorders: acrophobia (North and North, 1996), agoraphobia (North et al., 1997), spider phobia (Carlin et al., 1997), fear of public speaking (North et al., 1998), claustrophobia (Botella et al., 2000, 2004) and eating disorders (Perpiñá et al., 1999; Riva et al., 2002).

The aim of the present study is to test whether adding a component of treatment on body image in CBT for eating disorders produces a greater improvement than CBT alone. Given our previous studies (Perpiñá et al., 1999) we use VR techniques for the treatment of body image.

For the present research we carried out a controlled study with participants diagnosed with eating disorders in which we compared the CBT for eating disorders to the CBT for eating disorders plus a specific treatment component for body image using VR. Posttreatment and one year follow-up results are presented. Statistical and clinical improvement for both treatment situations are analyzed and compared.

\section{Method}

\subsection{Sample and participant selection}

The sample came from the Outpatient Program for Eating Disorders at the Hospital Provincial in Castellón, Spain. Inclusion criteria were as follows: participants diagnosed with eating disorders according to DSM-IV-TR (APA, 2000) criteria. Exclusion criteria were Body Mass Index (BMI) $<16$, substance abuse, high suicide risk and serious personality disorders. The sample comprised 34 female patients with the following diagnoses: 17 with BN (16 purgative types and 1 non-purgative type), 12 with Eating Disorder not Otherwise Specified (EDNOS) and 5 with AN (2 purgative types and 3 restrictive types). Partcipants' age range was broad: 15-40 years old with an average age of 21.82 (5.75). BMI ranged from 16 to 32 with an average of 21.5 (4.28) and the length of time with eating disorders was 1-16 years with an average of 4.17 (4.1). As for secondary psychopathology, $23.5 \%$ of participants presented personality disorders and $32 \%$ of them had another Axis I disorder (15\% matched Major Depressive Disorder criteria, $12 \%$ Posttraumatic Stress Disorder, and 5\% other Anxiety Disorders). As for the participants' educational level, $29 \%$ had college-level education (including current students), $47 \%$ had high school education (including current students), and $24 \%$ had primary school education. They volunteered for the study and informed consent was given.

\subsection{Assessments and measures}

SCID I Interview (First et al., 2002). This is an interview for making the major DSM-IV-TR (APA, 2000) Axis I diagnoses. It is widely used in mental health studies and offers good psychometric properties: Kappa 0.66, demonstrating reliability (Lobbestael et al., 2011).

SCID-II Interview (First et al., 1997). This is an interview for making DSM-IV-TR (APA, 2000) Axis II Personality Disorder diagnoses. It includes 119 questions and has a Kappa 0.74, demonstrating reliability for admitted patients (First et al., 1999).

The primary outcome measure was Body Image. But, Body Image is a multidimensional construct. In this research we selected different measures to assess the different dimensions of this construct because we expected changes in all of them.

Body Attitude Test (BAT) (Probst et al., 1995). This is a scale for evaluating dissatisfaction with one's body. It includes 20 items in Likert format ranging from 1 (never) to 5 (always). The score ranges from 0 to 100 . In the general Spanish population the alpha was 0.92 demonstrating internal consistency with testretest reliability of 0.91 (Gila et al., 1999).

Body Image Automatic Thoughts Questionnaire (BIATQ) (Cash et al., 1987) This measures the cognitive component of body image. It has 52 items in Likert format ranging from 1 (never) to 5 (always) covering automatic thoughts about physical appearance. In the general Spanish population (Perpiñá et al., 2003) it has a 0.91 internal consistency on the general scale, 0.97 on the negative scale, and 0.91 on the positive scale. Test-retest reliability in the general Spanish population is 0.91 for the general scale, 0.88 for the negative scale, and 0.76 for the positive scale.

Body Areas Satisfaction Scale (BASS) (Cash, 1991). This measures the degree of satisfaction and dissatisfaction with regard to 10 body areas. It contains 10 items which are scored on a Likert scale 1 (very unsatisfied) to 5 (very satisfied). It presents 0.79 and 0.78 internal consistency for men and women, respectively (Cash, 1991)

Situational Inventory of Body-Image Dysphoria (SIBID) (Cash, 1994). This instrument collects body discomfort and dissatisfaction reactions triggered by behavior or situations. It comprises 49 items in Likert format ranging from 0 (never) to 4 (always). It has a 0.97 internal consistency in the general Spanish population and 0.86 test-retest reliability (Perpiña et al., 2006).

As a secondary measure of result we also expected changes in eating disorders psychopathology.

The Bulimic Investigatory Test, Edinburgh (BITE) (Henderson and Freeman, 1987). This evaluates the cognitive and behavioral characteristics of binge eating disorder and BN. It has 33 items divided into 2 subscales. The items in the Symptom subscale are formulated in a dichotomous format (yes/no), whereas the items in the Severity subscale are formulated in a Likert-type response format (with 5 or 7 options, depending on the item). It has a 0.68 test-retest reliability for BN. It features two scales: the Symptom scale, with 0.96 internal consistency and the Severity scale, with 0.62 internal consistency.

The Eating Attitudes Test (EAT) (Garner and Garfinkel, 1979; Garner et al. 1982). It evaluates attitudes and behavior associated with AN. It has 40 items organized into 7 factors, which are answered on a Likert scale of 6 points. The authors have established a cutoff point of 30 for clinical symptomatology. Testretest reliability for a two to three week interval is 0.84 (Carter and Moss, 1984). In the general Spanish population it has 0.93 internal consistency for AN and 0.92 for BN (Castro et al., 1991).

Weekly evaluation of symptoms. A weekly symptom record was designed for this research for the evaluation of clinical variations in patients, specifically the frequency of binges and the frequency of purgative behavior. It also assesses the degree of fear and avoidance of forbidden food on a Likert scale (range 0-5) as well as the degree of discomfort with one's body in front of a mirror on a Likert scale (range $0-10$ )

\subsection{Treatment}

Two treatment components were determined.

Component 1: CBT for eating disorders. Depending on diagnosis of CBT for BN (Wilson et al., 1997) or CBT for AN (Garner et al., 1997). The EDNOS cases were partial AN or BN, so they received treatment according to the diagnosis.

Component 2: CBT for body image in eating disorders using VR (Perpiñá et al., 2000). In this study, we adapted the CBT for body image disturbances in eating disorders (Butters and Cash, 1987; Perpiñá et al., 2000), organizing it in three stages and extending it to 15 CBT group sessions and 8 individual psychotherapy sessions with VR techniques with the following stages:

Stage I: Sessions 1-3. The objective of this stage was for participants to become aware of their body image issues, to differentiate between their body and body image, and to learn that discomfort with their bodies cannot be suppressed by changing their bodies but rather by changing their body image. Participants learned about the psychoeducational principles of body image distortion, the consequences of negative body image and how body image is shaped, what weight is, how to maintain one's weight, tricks and lies in advertising, the main cultural factors for dissatisfaction with one's body, etc. At this stage, environments 1, 2, and 3 are used for 3 sessions.

Stage II: Sessions 4-13. The general objective of this stage was to change attitudes and beliefs about body and appearance, and to alter the avoidance and security issues which underlie body image issues. The basics of cognitive therapy as adapted for body image issues were explained. In this stage, participants were exposed to social situations related to body image disorders, and they were taught how to face them in an adaptive way. In the exposure to the mirror, new positive relationships between participants and their bodies were established through activities designed to alter their interpretation of 
their bodies. Finally, this stage addresses self-awareness and self-esteem. Participants interact with virtual environments four and five for five sessions. Stage III: Sessions 14-15. The general objective of this stage was consolidating the achievements of the previous stages, generating an internal attribution of treatment results, and preparing for medical clearance and relapse prevention. In this stage, participants do not interact with virtual environments.

\subsection{Virtual environments}

Five virtual environments were used (Perpiñá et al., 2003). Following is a summary of the virtual environments and their respective therapeutic objectives. Area 1, Virtual scale and kitchen. The aim of this area is to distinguish and understand the concepts of real weight, subjective weight, desired weight, and healthy weight, and to raise patients' awareness of unrealistic "rules" they use to obtain their subjective weight. Area 2, Photograph area. The objective of this environment is for patients to understand that their "magic" weight number is value related to other variables such as gender, height, physical build, etc. Furthermore, the patients' tendency to compare themselves with other bodies is addressed and they are encouraged to project themselves in the future in each of the bodies represented. Area 3, Mirror area. The general aim of this environment is to observe and evaluate the participant's body image through discrepancy indexes between their body image and their real appearance, so that they perceive the oversizing of their body image as seen from the front and side and in various situations. The participant corrects this discrepancy and relates it to the negative attitudes and emotions toward their body image. The patient has to manipulate a 3D human figure increasing or decreasing different body areas until it represents her body image. In the other mirror, the patient's real body appears in a translucent 2D-image in order to overlap with the 3D figure. If both figures do not fit, the patient has to correct the 3D figure. In Area 4 there is a doorframe with several colored strips in it. The objective of this area is to pass sideways through the door, in such a way that it is necessary to remove the exact number of strips to open the accurate gap. Finally, in Area 5 different versions of one's body are presented. The aim of this area is for participants to become aware of the discrepancies between their ideal appearance, their real body, and their healthy body as well as how other people perceive them (Perpiñá et al., 2003).

\subsection{Apparatus}

The VR application used is thoroughly described in Perpiñá et al. (2003). This application was developed on WorldUp software with Sense8. The hardware consists of a desktop Pentium III PC, an AccelGraphics AccelEclipse graphic card and a head-mounted display (V6 by Virtual Research) with a 2D mouse.

\subsection{Design}

\section{Two treatment conditions were designed:}

Treatment condition 1. Standard CBT for Eating Disorders Treatment (SEDT): this condition included component 1 (CBT for Eating Disorders).

Treatment condition 2. CBT for Eating Disorders enhanced by CBT for body image, specifically the treatment component using VR techniques (SEDTBI). This condition included component 1 (CBT for Eating Disorders) and component 2 (CBT for Body Image).

In order to compare the effectiveness of both treatment conditions, measures were evaluated at three points: pre-treatment, post-treatment and one year follow-up. We compared the effectiveness of these conditions both from a statistical and a clinical point of view.

We carried out the following analyses: a multivariate analysis of variance for repeated measures, taking as an intra-subject factor the act of taking measures: pre-treatment, post-treatment, and follow-up.

Next, we performed an analysis of the clinical effectiveness of the intervention under both treatment conditions (Jacobson and Truax, 1991; Sheldrick et al., 2001; Lundgren et al., 2004). Two methods were used to demonstrate whether the treatment resulted in clinically significant change (Kendall et al., 1999). First, we observed that reliable change had been achieved (Reliable Change Index). Second we compared the difference between post-treatment clinical scores and the scores that healthy populations show for these measures. For this purpose we calculated the effect size of the differences between the scores using Hedges' g Index (Hedges and Olkin, 1985). Only when treatment has brought about a reliable change and the outcomes become similar to those for healthy population it can be considered clinically significant (Lundgren et al., 2004).

\subsection{Procedure}

Random sub-sampling was carried out. The assignment of treatment conditions was random as well. Sample selection, participant evaluations, random assignment to experimental groups, post-treatment assessment, and data analysis were all conducted by researchers blind to these experimental designs. One year after end of treatment there was an individual assessment session in which the patients completed again the assessment protocol. The participant evaluations and the follow-up assessment were conducted by researchers blind to experimental design.

We followed CONSORT recommendations. Ethical approval for carrying out this study was granted by the Hospital Ethics Committee.

Outpatient CBT for BN (Wilson et al., 1997) was carried out in a group with an eating disorder therapist and co-therapist. Nineteen two-hour weekly sessions took place. Outpatient CBT for AN (Garner et al., 1997) was individual treatment; one weekly session in Stage I and one biweekly session in stages II and III. A total of 23 sessions were carried out.

Outpatient CBT for Body Image in Eating Disorders was carried out in groups in 15 treatment sessions. The VR component was administered individually in eight one-hour weekly sessions. Patients were not administered pharmacological treatment except for two patients who had previous prescriptions (Paroxetine for one EDNOS participant and Bromacepan for one AN participant); the doses were maintained or reduced as needed. Treatment was always outpatient and participants did not receive any other treatment during the study.

\section{Results}

Thirty-four participants were evaluated and assigned to treatment conditions. In the first sessions, four participants who chose not to attend their therapy groups were thereby excluded from further treatment. These participants had severe personality disorders and the presence of Major Depressive Disorder in addition to Eating Disorder. Eleven of the 30 initial patients left treatment: four from the SEDTBI condition and seven from the SEDT condition. Because this was an initial study of a new treatment, the analyses were restricted to those who completed the treatment.

No significant pre-treatment differences were found between these conditions, a fact supported by independent t-test samples. At the one year follow-up, one participant dropped out of the SEDT condition. The final sample comprised 18 participants: 9 in the SEDT condition and 9 in the SEDTBI condition. Fig. 1 shows the sample evolution in a CONSORT diagram (Moher et al., 2001).

The results show that all participants improved their body image in a statistically significant way under both treatment conditions and that this improvement was maintained at the one year followup $\left(F_{(8,52)}=3.61, P<0.002, \eta^{2}=0.35,1-\beta=0.9\right)$. It is worth noting that SEDTBI patients showed more improvement that those in SEDT. A statistically significant interaction effect between condition treatment and the three measurement points occurred $\left(F_{(8,52)}=2.29\right.$, $\left.P<0.03, \eta^{2}=0.35,1-\beta=0.8\right)$. SEDTBI patients showed more posttreatment improvement, and this improvement continued to rise at the one year-follow up in terms of body attitudes (BAT) $\left(F_{(2,28)}\right.$ $=6.28, P<0.006, \eta^{2}=0.31,1-\beta=0.8 ; F_{(1,14)}=9.85, P<0.007, \eta^{2}$ $\left.=0.41,1-\beta=0.8 ; F_{(1,14)}=6.14, P<0.03, \eta^{2}=0.3,1-\beta=0.6\right)$ and in the frequency of negative automatic thoughts on body image (BIATQ) $\quad\left(F_{(1.57,21.11)}=5.27, \quad P<0.02, \quad \eta^{2}=0.2, \quad 1-\beta=0.8 ; \quad F_{(1,14)}\right.$ $=6.01, P<0.03, \eta^{2}=0.3,1-\beta=0.6 ; F_{(1.14)}=5.78, P<0.03, \eta^{2}=0.3$, $1-\beta=0.6)$. The same happened in body satisfaction (BASS) $\left(F_{(2,28)}\right.$ $=6.16, \quad P<0.006, \quad \eta^{2}=0.3, \quad 1-\beta=0.8 ; \quad F_{(1.14)}=13.73, \quad P<0.002$, $\left.\eta^{2}=0.5,1-\beta=0.9\right)$ and in discomfort caused by body-related situations (SIBID) $\left(F_{(1.66,23.33)}=3.45, P<0.05, \eta^{2}=0.0 .2,1-\beta=0.6\right.$; $\left.F_{(1,14)}=4.67, P<0.05, \eta^{2}=0.25,1-\beta=0.5\right)$, and statistical significance was attained at the one year-follow up. Table 1 shows the average and standard deviations in the measures.

At the post-treatment, all participants improved in the psychopathology eating disorders self-report measures. The participants in both conditions improved to a statistically significant degree and this improvement was maintained at the one year follow-up $\left(F_{(6,62)}=5.56, P<0.0001, \eta^{2}=0.7,1-\beta=0.9\right)$. SEDTBI participants showed much greater improvement than SEDT ones. However, this difference did not reach statistical significance 


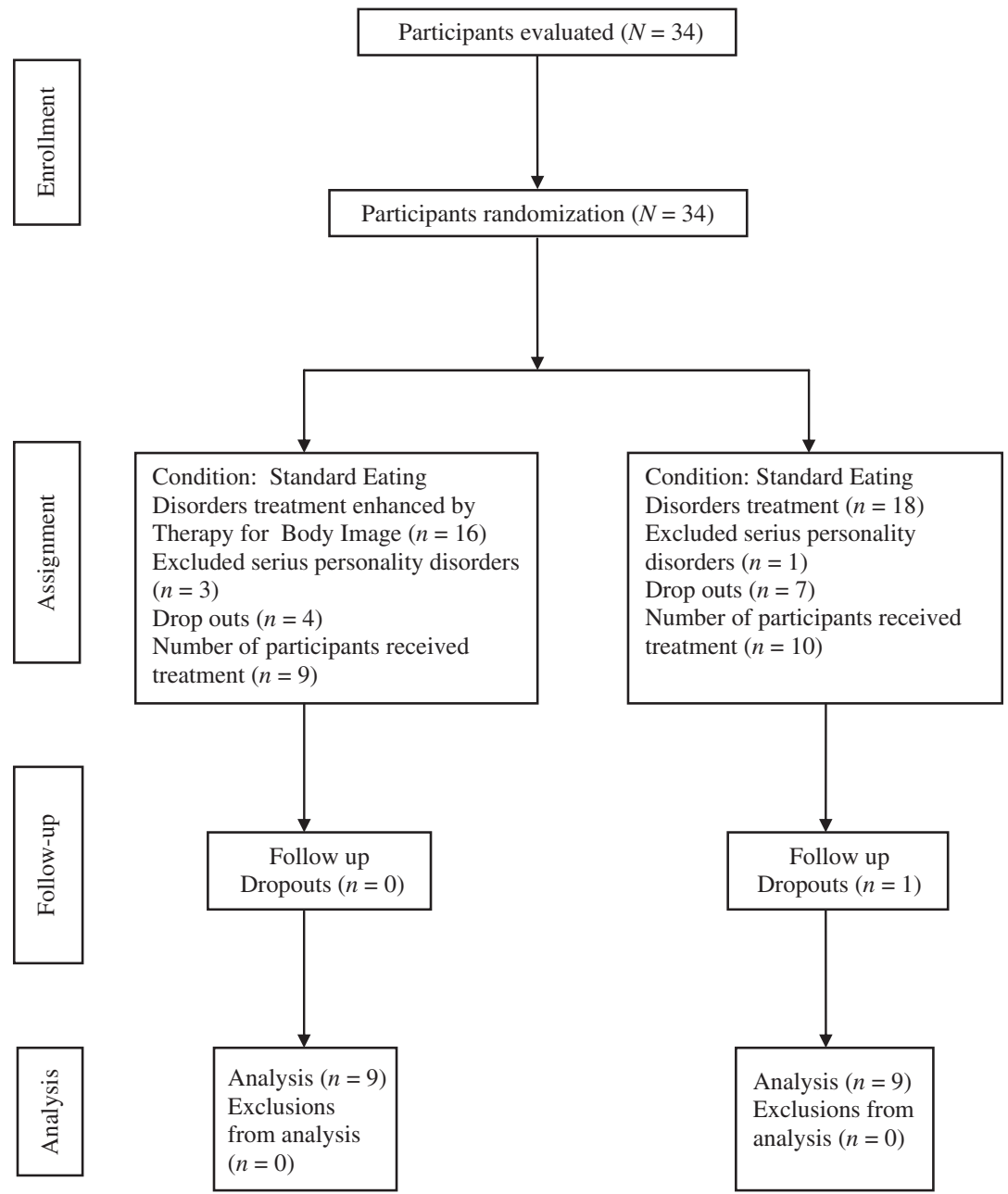

Fig. 1. Sample evolution throughout treatment.

Table 1

Pre, post-treatment, and follow-up measure values.

\begin{tabular}{|c|c|c|c|c|c|c|c|c|c|c|c|c|}
\hline \multirow[t]{3}{*}{ Variable } & \multicolumn{4}{|c|}{ Pre-treatment } & \multicolumn{4}{|c|}{ Post-treatment } & \multicolumn{4}{|c|}{ Follow-up } \\
\hline & \multicolumn{2}{|c|}{ SEDTBI } & \multicolumn{2}{|l|}{ SEDT } & \multicolumn{2}{|c|}{ SEDTBI } & \multicolumn{2}{|l|}{ SEDT } & \multicolumn{2}{|c|}{ SEDTBI } & \multicolumn{2}{|l|}{ SEDT } \\
\hline & $M$ & S.D. & $M$ & S.D. & $M$ & S.D. & $M$ & S.D. & $M$ & S.D. & $M$ & S.D. \\
\hline BIATQ & 78.9 & 21.4 & 64.5 & 30.3 & 7 & 39.6 & 49.4 & 42.4 & -5.4 & 21.6 & 33.6 & 43.6 \\
\hline BAT & 66.4 & 10 & 61.1 & 14.8 & 36.2 & 16.8 & 60.1 & 24.1 & 29.5 & 12 & 46.2 & 23.3 \\
\hline BASS & 19.8 & 2.7 & 21.7 & 4.8 & 27.5 & 4.3 & 24.8 & 5.8 & 30.1 & 2.10 & 23.7 & 5.1 \\
\hline SIBID & 147.1 & 22.8 & 138.2 & 23.3 & 83.5 & 41.9 & 118.7 & 46.2 & 64.4 & 37.7 & 103.7 & 50.5 \\
\hline BITE & 25.8 & 9.7 & 24.1 & 8.5 & 8.2 & 6.1 & 16.1 & 8.3 & 4.5 & 4.2 & 15.5 & 10.3 \\
\hline Symptoms & 18.4 & 5.6 & 17.7 & 4.3 & 6.5 & 5.8 & 12.4 & 6.9 & 3.3 & 2.5 & 10.1 & 7.6 \\
\hline Severity & 6.6 & 3.8 & 6.3 & 4.6 & 1.6 & 1.4 & 3.6 & 3 & 1.2 & 1.8 & 2.4 & 3 \\
\hline EAT-40 & 47.2 & 15.6 & 53.3 & 13.2 & 17 & 9.4 & 34.4 & 25.5 & 12 & 7.3 & 28.1 & 19.2 \\
\hline DM & 7.7 & 0.8 & 6.8 & 2.8 & 4 & 3.1 & 7.3 & 2.3 & 2.7 & 2.1 & 5.3 & 3.1 \\
\hline Vomit day & 1.5 & 1.1 & 0.6 & 0.7 & 0 & 0 & 0.3 & 0.5 & 0 & 0 & 0.2 & 0.3 \\
\hline FA & 4.1 & 0.7 & 3.8 & 1.1 & 2.8 & 1.3 & 4.4 & 0.5 & 1.5 & 1.1 & 2.8 & 1.8 \\
\hline Binge day & 1.8 & 1.6 & 1 & 1.1 & 0 & 0 & 0.1 & 0.3 & 0 & 0 & 0.1 & 0.2 \\
\hline FFF & 4.1 & 0.7 & 4 & 0.8 & 2.6 & 1.2 & 4.1 & 0.8 & 1.3 & 0.5 & 3.1 & 1.5 \\
\hline
\end{tabular}

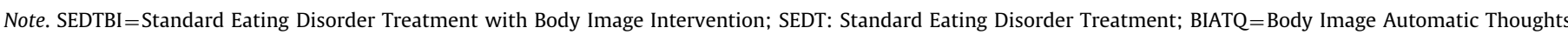

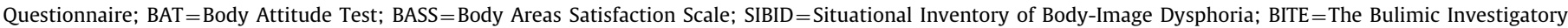
Test Edinburgh; EAT=Eating Attitudes Test; $\mathrm{MII}=$ Discomfort in the Mirror; FA=Food Avoidance; FFF=Fear of Forbidden Food.

$\left(F_{(6,62)}=1.24, P<0.3, \eta^{2}=0.1,1-\beta=0.5\right)$. Univariate analysis of each instrument shows that in BN symptomatology measured according to the BITE Symptoms Scale $\left(F_{(2,32)}=3.78, P<0.03\right.$, $\left.\eta^{2}=0.2, \quad 1-\beta=0.6 ; \quad F_{(1.16)}=6.20, \quad P<0.02, \quad \eta^{2}=0.3, \quad 1-\beta=0.6\right)$ and $\operatorname{BITE}\left(F_{(2,32)}=3.31, P<0.05, \eta^{2}=0.2,1-\beta=0.6 ; F_{(2,32)}=5.83\right.$,
$\left.P<0.03, \eta^{2}=0.3,1-\beta=0.6\right)$, there was indeed a statistically significant higher improvement at post-treatment in SEDTBI participants than in SEDT ones. This differential improvement in bulimic symptomatology was maintained at the one year followup (BITE Symptoms Scale) $\left(F_{(1,16)}=4.75, \quad \mathrm{P}<0.04, \quad \eta^{2}=0.2\right.$, 
$1-\beta=0.5)$. The difference between the conditions did not reach statistical significance in EAT.

The weekly evaluation results showed that all participants had improved at post-treatment and at the one year follow-up. However, SEDTBI participants showed greater improvement in the behavior recorded. This improvement was statistically significant and occurred post-treatment; improvement increased at the one year follow-up, specifically in the post-treatment "being able to look at oneself in the mirror" item, $\left(F_{(2,15)}=3.94, P<0.04\right.$, $\left.\eta^{2}=0.3,1-\beta=0.6 ; F_{(1,16)}=8.13, P<0.01, \eta^{2}=0.3,1-\beta=0.8\right)$, at the one year follow-up $\left(F_{(1,16)}=5.84, P<0.03, \eta^{2}=0.3,1-\beta=0.6\right)$, in post-treatment "purge frequency" $\left(F_{(1.25,18.86)}=6.08, P<0.02\right.$, $\left.\eta^{2}=0.3,1-\beta=0.7 ; F_{(1.15)}=7.20, P<0.01, \eta^{2}=0.3,1-\beta=0.7\right)$, and at the one year follow-up $\left(F_{(1,15)}=5.45, P<0.03, \eta^{2}=0.3\right.$, $1-\beta=0.6)$, in post-treatment "avoidance of forbidden food" $\left(F_{(2,10)}=3.84, P<0.05, \eta^{2}=0.4,1-\beta=0.5 ; F_{(1,15)}=5.59, P<0.03\right.$ $\left.\eta^{2}=0.3,1-\beta=0.6\right)$, and at one year follow-up $\left(F_{(1,15)}=4.62\right.$, $\left.P<0.05, \quad \eta^{2}=0.3, \quad 1-\beta=0.5\right)$. In "fear of forbidden food" $\left(F_{(2,10)}=3.37, P<0.46\right)$, statistical significance was not reached.

In order to analyze the clinical effectiveness of each of the treatment conditions, we observed that the post-treatment and one year follow-up changes brought about by the SEDTBI condition were completely reliable. We calculated the Reliable Change Index (RCI) and obtained a 95-98\% reliability index for all body image measures: BAT, BIATQ, SIBID, BASS and all of the BITE and EAT eating disorders psychopathology measures. Table 2 shows the RCI values.

The post-treatment and one year follow-up changes brought about by SEDT were completely reliable (99\% reliability index) for the eating disorders psychopathology measures (BITE and EAT). However, change in Body Image measures (BAT, BIATQ, SIBID, BASS) cannot be considered reliable.

Post-treatment and one year follow-up SEDTBI participants showed clinically significant improvement (change had a 95-98\% reliability index) and all body image and eating disorders measures scores were similar to those of the healthy population; there were no statistically significant differences in BAT, BASS BIATQ or SIBID. In EAT, participants showed better scores than the normal population, and in BITE, normalization was achieved at the one year follow-up. Table 3 shows t tests and effect size (Hedges' g).

By contrast, SEDT participants did not show clinically significant improvement at post-treatment or one year follow-up; no reliable change occurred; furthermore, there were differences with regard to healthy populations in body image measures (BAT, BASS, SIBID, and

Table 2

Reliable Change Index values.

\begin{tabular}{|c|c|c|c|c|}
\hline \multirow[t]{2}{*}{ Variable } & \multicolumn{2}{|c|}{ Post-treatment } & \multicolumn{2}{|c|}{ Follow-up } \\
\hline & $\begin{array}{l}\text { SEDTBI } \\
R C I\end{array}$ & $\begin{array}{l}\text { SEDT } \\
R C I\end{array}$ & $\begin{array}{l}\text { SEDTBI } \\
R C I\end{array}$ & $\begin{array}{l}\text { SEDT } \\
R C I\end{array}$ \\
\hline BIATQ & $4.49^{* * *}$ & 0.94 & $10.96^{* * *}$ & 1.92 \\
\hline BAT & $4.51^{* * k}$ & 0.14 & $5.51^{* * * *}$ & 2.22 \\
\hline BASS & 1.86 & 0.75 & $2.50^{*}$ & 0.48 \\
\hline SIBID & $2.96^{* * *}$ & 0.9 & $3.85^{* * *}$ & 1.60 \\
\hline BITE & $8.56^{\text {*** }}$ & $3.9^{* * *}$ & $10.3^{\text {*** }}$ & $4.1^{* * *}$ \\
\hline EAT-40 & $15.7^{* * *}$ & $12.4^{* * *}$ & $17.7^{* * *}$ & $12.77^{* * *}$ \\
\hline
\end{tabular}

Note. $\mathrm{RCI}=$ Reliable Change Index; $\mathrm{BIATQ}=$ Body Image Automatic Thoughts Questionnaire; BAT =Body Attitude Test; BASS=Body Areas Satisfaction Scale; SIBID = Situational Inventory of Body-Image Dysphoria; BITE = Bulimic Investigatory Test Edinburgh; EAT=Eating Attitudes Test; SEDTBI=Standard Eating Disorder Treatment with Body Image Intervention; SEDT: Standard Eating Disorder Treatment.

$$
\begin{aligned}
& { }^{*} P<0.05 . \\
& { }^{* *} P<0.01 .
\end{aligned}
$$

BIATQ) and in EAT and BITE eating disorders measures. Table 4 shows $t$ tests and effect size (Hedges' $g$ ).

\section{Discussion}

The CBT program for eating disorders enhanced by a body imagespecific component using VR techniques was shown to be more efficient than CBT alone. The body image-specific component using VR techniques boosts efficiency and accelerates the CBT change process for eating disorders; it results in greater improvement than when body image is not addressed.

This improvement was greater both in terms of an analysis of statistically significant differences and an analysis of clinically significant change. Under the body image treatment condition, participants presented a post-treatment reduction of eating disorder and body image psychopathology to levels similar to those of the healthy population. No clinically significant improvement was obtained under the condition with no specific intervention on body image.

The results obtained reveal the advantage of including a treatment component addressing body image disturbances in the eating disorder general treatment protocol. It results in greater improvement in attitudes, thoughts, emotions, and behavior related to one's body and physical appearance, and likewise has a positive effect on eating disorder psychopathology. Moreover, body image treatment accelerates the change process and maximizes the

Table 3

Post-treatment and one year follow-up differences between the scores of parti-

\begin{tabular}{|c|c|c|c|c|c|c|c|c|}
\hline \multirow[t]{2}{*}{ Variable } & \multicolumn{4}{|c|}{ Post-treatment } & \multicolumn{4}{|c|}{ Follow-up } \\
\hline & $t$ & d.f. & $P<$ & $g^{\mathrm{a}}$ & $t$ & d.f. & $P<$ & $g^{a}$ \\
\hline BIATQ & 1.48 & 106 & $n s$ & $\mathrm{a}$ & 1.47 & 106 & $n s$ & $\mathrm{a}$ \\
\hline BAT & 0.61 & 222 & $n s$ & $\mathrm{a}$ & 0.50 & 222 & $n s$ & $\mathrm{a}$ \\
\hline BASS & 0.0 & 106 & $n s$ & $\mathrm{a}$ & 1.24 & 106 & $n s$ & $\mathrm{a}$ \\
\hline SIBID & 0.56 & 222 & $n s$ & $\mathrm{a}$ & 0.81 & 222 & $n s$ & $\mathrm{a}$ \\
\hline BITE & 3.57 & 37 & 0.001 & $1.30^{\mathrm{b}}$ & 1.07 & 37 & $n s$ & $\mathrm{a}$ \\
\hline EAT-40 & 1.02 & 82 & $n s$ & a & 4.63 & 82 & 0.001 & $1.62^{\mathrm{b}}$ \\
\hline
\end{tabular}
cipants under SEDTBI condition and healthy population.

Note. SEDTBI = Standard Eating Disorder Treatment with Body Image Intervention; BIATQ = Body Image Automatic Thoughts Questionnaire; BAT = Body Attitude Test: BASS = Body Areas Satisfaction Scale; SIBID = Situational Inventory of Body-Image Dysphoria; BITE=The Bulimic Investigatory Test Edinburgh; EAT-40=Eating Attitudes Test; $n s$ : not statistically significant.

${ }^{a}$ Hedge's $g$ calculated only when $P<0.05$.

b This participant presented better scores than healthy population.

Table 4

Post-treatment and one year follow-up differences between the scores of parti-

\begin{tabular}{|c|c|c|c|c|c|c|c|c|}
\hline \multirow[t]{2}{*}{ Variable } & \multicolumn{4}{|c|}{ Post-treatment } & \multicolumn{4}{|c|}{ Follow-up } \\
\hline & $t$ & d.f. & $P<$ & $g$ & $t$ & d.f. & $P<$ & $g^{\mathrm{a}}$ \\
\hline BIATQ & 2.33 & 106 & 0.01 & 0.80 & 1.13 & 106 & $n s$ & $\mathrm{a}$ \\
\hline BAT & 4.48 & 222 & 0.001 & 1.52 & 2.23 & 222 & 0.01 & 0.75 \\
\hline BASS & 1.48 & 106 & 0.05 & 0.50 & 1.75 & 106 & 0.05 & 0.60 \\
\hline SIBID & 3.11 & 222 & 0.005 & 1.05 & 2.01 & 222 & 0.005 & 0.68 \\
\hline BITE & 7.50 & 37 & 0.001 & 2.79 & 6.03 & 37 & 0.001 & 2.24 \\
\hline EAT-40 & 4.38 & 82 & 0.001 & 1.51 & 3.23 & 82 & 0.001 & 1.11 \\
\hline
\end{tabular}
cipants under SEDT condition and healthy population.

Note. $\mathrm{SEDTBI}=$ Standard Eating Disorder Treatment; BIATQ = Body Image Automatic Thoughts Questionnaire; BAT=Body Attitude Test; BASS=Body Areas Satisfaction Scale; SIBID=Situational Inventory of Body-Image Dysphoria; $\mathrm{BITE}=$ The Bulimic Investigatory Test Edinburgh; EAT-40=Eating Attitudes Test; $n s$ : not statistically significant.

a Hedge's $g$ calculated only when $P<0.05$. 
results of $\mathrm{CBT}$ as used for eating disorders. In other words, the improvement occurs much earlier when body image issues are treated. Bearing in mind the importance of body image as a maintenance and prognosis factor in eating disorders (Shisslak and Crago, 2001; Stice and Shaw, 2002), achieving improvement and normalization is highly significant in terms of preventing potential relapses.

These results are consistent with those obtained by other authors (Perpiñá et al., 2000; Cash and Hrabosky, 2004; Nye and Cash, 2006) who claim that superficial intervention is not sufficient to improve and normalize body image issues; a specific treatment addressing every dimension of body image disturbances (attitudinal, perceptive and emotional) is required.

Currently, other authors (Fairburn et al., 2009) are demonstrating a need to enhance treatment for eating disorders with other CBT components addressing perfectionism, interpersonal problems, and self-esteem. With the present study concluded, a structured and thorough body image intervention is recommended. However, we do not believe that all cases or patients will need a thorough intervention on body image; in some cases, body image does not play a central role in eating disorder persistence. Moreover, this study supports the advantages of using CBT for eating disorders to address not only the current symptoms and signs maintaining eating disorder, but also to uncover the etiological factors at the core of eating disorders (Fairburn et al., 2003), such as body image disturbances.

Few studies have conducted a controlled analysis to discover the advantages of specific, structured intervention on body image in patients with eating disorders (Farrell et al., 2006). The present study included a structured and controlled intervention from the start of treatment to follow-up, which allowed us to control external variables such as external treatments, vital changes, etc. One of the strengths of this study is the sample used, which comes from a public mental health institution, i.e. participants diagnosed with $\mathrm{AN}, \mathrm{BN}$, and EDNOS. Inclusion criteria were very broad, so it is safe to state that the sample is representative of patients seen in daily clinical practice (Mahon, 2000; Bell, 2001; Hass and Clopton, 2003). Conducting a one year follow-up also allowed us to demonstrate that the results are consistent and that they evolved as expected, which is a highly relevant aspect given eating disorder relapse rates.

One of the limitations of this work is that those in the treatment condition SEDTBI received more sessions therapy during treatment. In a previous study, to avoid this limitation, we added relaxation sessions to balance the number of sessions in the treatment conditions. It is shown that CBT for body image is more effective when applied using VR techniques (Perpiñá et al., 1999). Our experience tells us that a greater number of sessions do not indicate greater improvement in eating disorders unless we treat such central aspects of the disorder as body image. Another limitation of this study is attrition during the treatment. However, the attrition rate in SEDTBI was 50\% lower than in SEDT. We also observed this adherence to treatment effect in other research using new technologies such as VR (Perpiñá et al., 2004). The data in this study supports the effectiveness of VR compared to "traditional" strategies, especially in the treatment of body image disturbances (Perpiñá et al., 2001; Riva et al., 2002). The features of this tool seem compatible with the therapeutic requirements of these highly complex disorders. One of the limitations of this study was that the exclusion of patients with severe personality disorders was performed after beginning treatment. Hence, the treatment conditions did not have the same number of participants. Until treatment has begun, we cannot know how treatments in people with severe personality disorders can interfere and disrupt the therapy (Linehan, 1993). Another limitation was the small number of participants.
However, the size of the sample is similar to that found in other studies with eating disorder outpatient clinical samples (Nye and Cash, 2006). Another limitation was that it was not possible to analyze the results in detail according to the participants' diagnoses. The difficulty in administering structured and homogeneous treatments to patients diagnosed with eating disorders is well known. This is demonstrated by the fact that only a few existing studies feature a differential analysis of the inclusion of a body image component to the conventional treatment for eating disorders (Nye and Cash, 2006). In a future study we must determine whether the treatment of body image is as important in patients with $\mathrm{AN}, \mathrm{BN}$, and Binge Eating Disorders. To do this, we will need larger sample and a multi-centre design. Another issue is that this study was conducted in a clinical setting with therapists proficient in the use of VR; futures studies should consider the training required for non-expert therapists.

This work presents a major clinical implication: it is necessary to evaluate and treat disorders of body image using VR techniques in clinical practice, hence making it necessary to train mental health specialists in this type of technology.

\section{Acknowledgment}

This work was partially funded by the CIBER Fisiopatología de la Obesidad y Nutrición, the Hospital Provincial of Castellon and the Ministry of Health and Consumption (FIS) (99/0997). CIBER Fisiopatología de la Obesidad y Nutrición is an initiative of ISCIII.

\section{References}

American Psychiatric Association, 2000. Diagnostic and Statistical Manual of Mental Disorders, 4th ed., text rev. APA, Washington, DC.

Bell, L., 2001. What predicts failure to engage in or drop out from treatment for bulimia nervosa and what implications does this have for treatment? Clinical Psychology and Psychotherapy 8, 424-435.

Botella, C., Baños, R., Villa, H., Perpiña, C., García-Palacios, A., 2000. Virtual reality in the treatment of claustrophobic fear: a controlled, multiplebaseline design. Behavior Therapy 31, 583-595.

Botella, C. Villa, H., García-Palacios, A., Baños, R.M., Perpiñá, C , Alcañiz, M., 2004. Clinically significant virtual environments for the treatment of panic disorder and agoraphobia. Cyberpsychology \& Behavior 7 (5), 527-535.

Butters, J.W., Cash, T.F., 1987. Cognitive-behavioral treatment of women's bodyimage dissatisfaction. Journal of Consulting and Clinical Psychology 55 889-897.

Carlin, A.S., Hoffman, H.G., Weghorst, S., 1997. Virtual reality and tactile augmentation in the treatment of spider phobia: a case study. Behaviour Research and Therapy 35, 153-158.

Carter, P.I., Moss, R.A., 1984. Screening for anorexia and bulimia nervosa in a college population: problems and limitations. Addictive Behaviours 9, 417-419.

Cash, T.F., 1991. Body Image Therapy: a Program for Selfdirected Change. Guilford Press, New York.

Cash, T.F., 1994. The situational inventory of body- image dysphoria: contextual assessment of a negative body image. The Behavior Therapist 17, 133-134.

Cash, T.F., Grant, J.R., 1996. Cognitive-behavioral treatment of body-image disturbances. In: Hersen, M., Hesselt, V.Van (Eds.), Sourcebook of Psychological Treatment Manuals for Adult Disorders. Plenum Press, New York, pp. 567-614.

Cash, T.F., Hrabosky, J.I., 2004. Treatment of body image disturbances. In: Thompson, J.K. (Ed.), Handbook of Eating Disorders and Obesity. Wiley Hoboken, pp. 515-541.

Cash, T.F., Lewis, R.J., Keeton, P., 1987. Development and validation of the Body Image Automatic Thoughts Questionnaire. Paper presented at the Annual meeting of the Southeastern Psychological Association, Atlanta, USA

Castro, J., Toro, J., Salamero, M., Guimerá, E., 1991. The Eating Attitudes Test: validation of the Spanish version. Psychological Assessment 7, 175-190.

Fairburn, C.G., 2002. Cognitive-behavioral therapy for bulimia nervosa. In: Fairburn, C.G., Brownell, K.D. (Eds.), Eating Disorders and Obesity: A Comprehensive Handbook, 2nd ed. Guilford Press, New York, pp. 233-237.

Fairburn, C., Cooper, G., Doll, Z., O’Connor, M.E., Bohn, K., Hawker, D.M., Wales, J.A., Palmer, R.L., 2009. Transdiagnostic cognitive behavioral therapy for patients with eating disorders: a two-site trial with 60 week follow-up. American Journal of Psychiatry 166, 311-319.

Fairburn, C.G., Cooper, Z., Shafran, R., 2003. Cognitive behaviour therapy for eating disorders: a 'transdiagnostic' theory and treatment. Behaviour Research and Therapy 41, 509-528. 
Fairburn, C.G., Peveler, R.C., Jones, R., Hope, R.A., Doll, H.A., 1993. Predictors of 12-month outcome in bulimia nervosa and the influence of attitudes to shape and weight. Journal of Consulting and Clinical Psychology 61, 696-698.

Farrell, C., Shafran, R., Lee, M., 2006. Empirically evaluated treatments for body image disturbance: a review. European Eating Disorders Review 14, 289-300.

First, M.B., Gibbon, M., Spitzer, R.L., Williams, J.B.W., Benjamin, L.S., 1997. Structure Clinical Interview for DSM-IV Axis II Personality Disorders, (SCID-II). American Psychiatric Press, Washington.

First, M.B., Gibbon, M., Spitzer, R.L., Williams, J.W., Benjamin, L.S., 1999. Entrevista clínica estructurada para los trastornos de la personalidad del eje II del DSMIV-TR. Masson, Barcelona.

First, M.B., Spitzer, R.L., Gibbon, M., Williams, J.B.W., 2002. Structured Clinical Interview for DSM-IV-TR Axis I Disorders, Research Version, Non-patien Edition. Biometrics Research, New York State Psychiatric Institute, New York.

Garner, D.M., 2002. Body image and anorexia nervosa. In: Cash, T.F., Pruzinsky, T. (Eds.), Body Image: A Handbook of Theory, Research, and Clinical Practice. Guilford Press, New York, pp. 295-303.

Garner, D.M., Garfinkel, P.E., 1979. The Eating Attitudes Test: an index of the symptoms of anorexia nervosa. Psychology and Medicine 9, 273-279.

Garner, D.M., Olmstead, M.P., Bohr, Y., Garfinkel, P.E., 1982. The eating attitudes test: psychometric features and clinical correlates. Psychological Medicine 12, 871-878.

Garner, D.M., Vitousek, K.M., Pike, K.M., 1997. Cognitive-behavioral therapy for AN. In: Garner, D.M., Garfinkel, P.E. (Eds.), Handbook of Treatment for Eating Disorders. Guilford Press, New York, pp. 94-145.

Gila, A., Castro, J., Gómez, M.J., Toro, J., Salamero, M., 1999. The body attitudes test: validation of the Spanish version. Eating and Weight Disorders 4, 175-178.

Gleaves, D.H., Williamson, D.A., Barker, S.E., 1993. Confirmatory factor analysis of a multidimensional model of bulimia nervosa. Journal of Abnormal Psychology $102,173-176$

Hass, H.L., Clopton, J.R., 2003. Comparing clinical and research treatments for eating disorders. International Journal of Eating Disorders 33, 412-420.

Hedges, L.V., Olkin, I., 1985. Statistical Methods for Meta-Analysis. Academic Press, New York.

Henderson, M., Freeman, C., 1987. A self-rating scale for bulimia: the BITE. British Journal of Psychiatry 150, 18-24

Jacobson, N.S., Truax, P., 1991. Clinical significance: a stadistical approach to defining meaningful change in psychotherapy research. Journal of Consulting and Clinical Psychology 59 (1), 12-19.

Kendall, P.C., Marrs-Garcia, A., Nath, S.R., Sheldrick, R.C., 1999. Normative comparisons for the evaluation of clinical significance. Journal of Consulting and Clinical Psychology 53, 43-48.

Linehan, M.M., 1993. Cognitive-Behavioral Treatment of Borderline Personality Disorder. Guilford Press, New York.

Lobbestael, J., Leurgans, M., Arntz, A., 2011. Inter-rater reliability of the Structured Clinical Interview for DSM-IV Axis I Disorders (SCID I) and Axis II Disorders (SCID II). Clinical Psychology \& Psychotherapy 18 (1), 75-79.

Lundgren, D.J., Danoff-Burg. S., Anderson, D.A., 2004. Cogntitve-behavioral therapy for bulimia nervosa: an empirical analysis of clinical significance. International Journal of Eating Disorders 35, 262-274.

Mahon, J., 2000. Dropping out from psychological treatment for eating disorders: what are the Issues? European Eating Disorders Review 8, 198-216.

Moher, D., Schulz, K.F., Altman, D.G., 2001. The CONSORT statement: revised recommendations for improving the quality of reports of parallel group randomised trials. The CONSORT Group. The Lancet 357, 1191-1194.

National Institute for Clinical Excellence, 2004. Eating Disorders: Core Interventions in the Treatment and Management of Anorexia Nervosa, Bulimia Nervosa and Related Eating Disorders. Clinical Guideline No. 9. National Institute for Clinical Excellence, London. Available from 〈www.nice.org.uk/guidance/CG9〉.

North, M., North, S., 1996. Virtual reality psychotherapy. The Journal of Medicine and Virtual Reality 1, 28-32.

North, M., North, S., Coble, J., 1997. Virtual Reality Therapy. I.P.I. Press, Ann Arbor, Michigan.

North, M., North, S., Coble, J.R., 1998. Virtual reality therapy: an effective treatment for phobias. In: Riva, G., Widerhold, B.K., Molinari, E. (Eds.), Virtua Environments in Clinical Psychology and Neuroscience. IOS Press, Amsterdam.

Nye, S., Cash, T.F., 2006. Outcome of manualized cognitive-behavioral body image therapy with eating disordered women treated in a private clinical practice. Eating Disorders 14, 31-40.
Perpiñá, C., Borra, C., Baños, R. Botella, C. Quero, S., Jorquera, M., 2003. Psychometric properties of the Body Image Automatic Thoughts Questionnaire (BIATQ) in a Spanish population. Paper presented at the 37th Annual Convention of Association for Advancement of Behavior Therapy. Boston, USA.

Perpiñá, C., Botella, C., Baños, R.M., 2000. Imagen corporal en los trastornos alimentarios. Evaluación y tratamiento por medio de realidad virtual. Promolibro, Valencia.

Perpiñá, C., Botella, C., Baños, R.M., 2003. Virtual reality in eating disorders. European Eating Disorders Review 11, 261-278.

Perpiñá, C., Botella, C., Baños, R., Marco, J.H., Alcañiz, M., Quero, S., 1999. Body Image and virtual reality in eating disorders: exposure by virtual reality is more effective than the classical body image treatment? Cyberpsychology \& Behavior 2, 149-159.

Perpiñá, C., Baños, R., Botella, C., Marco, J.H., 2001. La realidad virtual como herramienta terapeútica: Un estudio de caso en las alteraciones de la imagen corporal en los trastornos alimentarios. Revista Argentina de Clínica Psicológica 10, 227-241.

Perpiña, C., Gallego, M.J., Botella, C., 2006. Psychometric properties of the Situational Inventory of Body-Image Dysphoria-Short form in a Spanish sample. Body Image: An International Journal of Research 3, 301-306.

Perpiñá, C., Marco, J.H., Botella, C., Baños, R., 2004. Tratamiento de la Imagen Corporal en los trastornos alimentarios mediante tratamiento cognitivocomportamental apoyado con realidad virtual: resultados al año de seguimiento. Psicología Conductual 12, 519-537.

Probst, M., Vandereycken, W., Van Coppenolle, H., Vanderlinden, J., 1995. The body attitude test for patients with an eating disorder: psychometric characteristics of a new questionnaire. Eating Disorders: The Journal of Treatment and Prevention 3, 133-145.

Riva, G., Bacchetta, M., Baruffi, M., Molinari, E., 2002. Virtual-reality-based multidimensional therapy for the treatment of body image disturbances in binge eating disorders: a preliminary controlled study. IEEE Transactions on Information Technology in Biomedicine 6, 224-234.

Rizzo, A.A., Wiederhold, M.D., Buckwalter, J.G., 1998. Basic issues in the use of virtual environments for mental health applications. In: Riva, G., Widerhold, B.K., Molinari, E. (Eds.), Virtual Environments in Clinical Psychology and Neuroscience. IOS Press, Amsterdam, pp. 21-42.

Rosen, J.C., 1996. Body image assessment and treatment in controlled studies of eating disorders. International Journal of Eating Disorders 20, 331-343.

Schwartz, M.D., Brownell, K.D., 2004. Obesity and body image. Body Image: An International Journal of Research 1, 43-56.

Sheldrick, R.C., Kendall, P.C., Heimberg, R.G., 2001. The clinical significance of treatments: a comparison of three treatments for conduct disordered children. Clinical Psychology: Science and Practice 8, 418-430.

Shisslak, C.M., Crago, M., 2001. Risk and protective factors in the development of eating disorders. In: Thompson, J.K., Smolak, L. (Eds.), Body Image, Eating Disorders, and Obesity in Youth: Assessment, Prevention, and Treatment. American Psychological Association, Washington, pp. 103-125.

Stice, E., 2002. Body image and bulimia nervosa. In: Cash, T.F., Pruzinsky, T. (Eds.) Body Image: A Handbook of theory, Research, and Clinical Practice. Guilford Press, New York, pp. 304-311.

Stice, E., Shaw, H.E., 2002. Role of body dissatisfaction in the onset and maintenance of eating pathology: a synthesis of research findings. Journal of Psychosomatic Research 53, 985-993.

Thompson, J.K., 1992. Body image: extent of disturbance, associated features, theoretical models, assessment methodologies, intervention strategies, and a proposal for a new DSM-IV category—Body Image Disorder. In: Hersen, M., Esisler, R.M., Miller, P.M. (Eds.), Progress in Behavior Modification. Sycamore Press, Sycamore IL, pp. 3-54.

Thompson, J.K., Heimberg, L.J., Clarke, A.J., 1996. Treatment of body image disturbances in eating disorders. In: Thompson, J.K. (Ed.), Body Image, Eating Disorders, and Obesity. American Psychological Association, Washington, pp. 303-320.

Vitousek, K.B., 2002. Cognitive-behavioral therapy for anorexia nervosa. In: Fairburn, C.G., Brownell, K.D. (Eds.), Eating Disorders and Obesity: a Comprehensive Handbook, 2nd ed. Guilford Press, New York, pp. 233-237.

Wilson, T.G., Fairburn, C.G., Agras, W.S., 1997. Cognitive-behavioral therapy for bulimia nervosa. In: Garner, D.M., Garfinkel, P.E. (Eds.), Handbook of Treatment for Eating Disorders. Guilford Press, New York, pp. 67-93. 